\title{
연구논문
}

중액선별법을 이용한 국내 저품위 리튬함유 광물의 선별연구

\author{
이정훈 ${ }^{1)} \cdot$ 김영진 $^{1)} \cdot$ 임진호 $^{1)} \cdot$ 전호석 $^{2)} \cdot$ 이재령 ${ }^{1{ }^{*}}$
}

\section{Heavy-medium Separation for Low Grade Li-bearing Mineral In Korea}

Junghoon Lee, Youngjin Kim, Jinho Lim, Hoseok Jeon and Jaeryeong Lee*

(Received 7 April 2014; Final version Received 20 May 2014; Accepted 19 June 2014)

\begin{abstract}
In order to improve grade of the domestic lepidolite (low grade Li-bearing mineral), heavy medium separation (HMS) was conducted with sample from Boam mine, in various range of size $(+4,4 \times 20,20 \times 65,-65$ mesh) and medium specific gravity $(2.65,2.70,2.75)$. As the result of HMS in crushed mineral by jaw crusher, separation efficiency of $\mathrm{Li}$ was higher in the range of $4 \times 20$ mesh at 2.70 of medium specific gravity $\left(\mathrm{Li}_{2} \mathrm{O}\right.$ grade: $4.32 \%$, $\mathrm{Li}_{2} \mathrm{O}$ recovery: $72.39 \%$ ). Whereas the case of +4 mesh, separation efficiency of $\mathrm{Li}$ was very low, regardless of medium specific gravity and recovery of $\mathrm{Li}_{2} \mathrm{O}$ drastically decreased in relation to increase in medium specific gravity. After grinding for +4 mesh minerals using disk pulverizer at $3 \mathrm{~mm}$ of distance of disk for liberation, HMS was carried out for ground minerals $\left(+4,4 \times 20\right.$ mesh). As the range of +4 mesh size, grade of $\mathrm{Li}_{2} \mathrm{O}$ was $4.8 \%$ (recovery: $80 \%$ ) at a 2.70 of medium specific gravity.
\end{abstract}

Key words : Lepidolite, Heavy medium separation(HMS), Recovery, Grade, Separation efficiency

요 약 : 국내 저품위 리튬함유광물로부터 인운모(lepidolite)에 포함된 $\mathrm{Li}_{2} \mathrm{O}$ 의 품위 향상을 위해 입도구간 $(+4$, $4 \times 20,20 \times 65$ mesh $)$ 및 매질 비중 $(2.65,2.70,2.75)$ 을 변화시켜 중액선별을 실시하였다. jaw crusher 분쇄 후 중액 실험 결과, $4 \times 20$ mesh에서 가장 높은 리튬 선별효율(매질비중 $2.70 \rightarrow \mathrm{Li}_{2} \mathrm{O}$ 품위 $4.32 \%$, 회수율 $72.39 \%$ )을 나타내 었다. +4 mesh는 매질 비중에 관계없이 리튬의 선별효율이 낮고, 매질 비중이 증가함에 따라 $\mathrm{Li}_{2} \mathrm{O}$ 의 회수율이 급격히 감소되었다. 이에 +4 mesh산물의 단체분리를 위해 disk pulverizer를 이용해 분쇄 후, 분쇄산물 $(+4,4 \times 20$ mesh)에 대해 중액선별을 실시하였고, +4 mesh, 매질비중 2.70 에서 $\mathrm{Li}_{2} \mathrm{O}$ 품위 $4.8 \%$, 회수율 $80 \%$ 가 가능하였다.

주요어 : 인운모, 중액선별, 회수, 품위, 선별효율

\section{서 론}

리튬(Lithium, Li)이 전기자동차에 이용되는 리튬이차 전지(Lithium secondary battery)의 주원료로 사용됨에 따라 소비량이 급증하고 있으며, 가격도 급격히 상승(1 톤 $\mathrm{Li}_{2} \mathrm{CO}_{3}$ 가격, 2000 년: $\$ 2,000 \rightarrow 2008$ 년: $\left.\$ 5,500\right)$ 하 고 있는 실정이다(Chon et al., 2010). 이에 일부 국가에 서는 자국의 리튬관련 산업을 보호하기 위한 대책을 마 련하고 있다. 하지만 리튬은 지역적 편중이 심한 광물 중 하나로 리튬관련 산업의 발전과 함께 자원무기화 현상이 발생될 것으로 예상된다(Ebensperger et al., 2005; Chon

1) 강원대학교 에너지·자원공학과

2) 한국지질자원연구원 광물자원연구본부

*Corresponding Author(이재령)

E-mail; jr-lee@kangwon.ac.kr

Address; Department of Energy \& Resources Engineering, Kangwon National University, Chuncheon, Korea et al., 2010; Kesler et al., 2012). 국내의 경우 2009년 기준 세계 3 위의 리튬 소비국이지만 리튬을 전량 수입에 의존하고 있어, 국내 리튬산업의 경쟁력 확보를 위한 대 책이 절실히 필요하다고 판단된다(Chon et al., 2010).

일반적으로 자연으로부터 리튬을 회수하는 방법은 광 석으로부터 회수와 염수로부터 회수하는 방법으로 나눌 수 있다. 이 중 광석으로부터 리튬을 생산하는 방법은 처 리공정이 복잡하고 산, 알칼리 등의 침출시약 사용량이 많 아 염수로부터 리튬을 회수하는 방법에 비해 약 3 배 정도 높은 생산비용 $\left(1\right.$ 톤 $\mathrm{Li}_{2} \mathrm{CO}_{3}$ 생산비용 $\rightarrow$ 염수: $\$ 2,300$, 광석: $\$ 6,400)$ 이 소요되고 있는 실정이다(Chon et al., 2010). 따라서 가격이 상승하고 있는 리튬의 안정적인 확보를 위해서는 광물로부터 회수되는 리튬의 처리비용 절감이 필요하다고 판단된다.

리튬을 함유한 광물을 분리하기 위한 일반적인 선별공 정은 광물종류(리티아 휘석(spodumene), 인운모(lepidolite) 
등)에 따라 약간씩 차이는 있지만 주로 파/분쇄 후 분급, 자력선별, 부유선별 등의 공정을 통해 리튬함유 광물을 회수하고 있다. 이러한 공정을 통해 회수되는 $\mathrm{Li}_{2} \mathrm{O}$ 의 품 위(\%)는 광물종류에 따라 차이가 있으며, $\mathrm{Li}_{2} \mathrm{O}$ 의 품위 가 $4 \%$ 이상일 때 경제적으로 활용가치가 있다고 알려져 있다(Bale and May, 1989; Wang and Yu, 2007; Choi et al., 2012; Lee et al., 2012). 하지만, 자력선별은 자성 특성을 가진 광물에 대해서만 적용이 가능하며, 부유선 별공정은 분쇄공정에 투입되는 에너지 소비가 높고 부선 시약을 사용함에 따라 다량의 폐수가 발생된다는 단점이 있다(Jeon et al., 2011). 이러한 이유에서 최근에는 전기 펄스와 광학선별을 이용한 리튬함유광물의 분리 연구가 진행되었다. 하지만 리튬을 함유하는 광물 중 매장량이 가장 많은 리티아 휘석에만 한정된 연구로서 리튬을 포 함하고 있는 타 광물에 대한 적용성이 검토되지 않았을 뿐만 아니라 광학특성이 비슷한 광물에는 선별이 제한되 는 단점이 있다(Brandt and Haus, 2010).

이에 본 연구에서는 리튬을 함유하는 대표광물 중 하 나인 인운모를 선별대상 광물로 선정하였다. 대상 시료 로부터 인운모 정광을 저비용으로 분리하기 위해 파쇄 후 입도구간별 하여 중액선별을 실시하여 이에 필요한 분쇄, 단체분리 및 중액선별공정의 조건을 도출하였고, 조건별 $\mathrm{Li}_{2} \mathrm{O}$ 의 품위, 회수율 및 리튬의 선별효율을 확인 하였다.

\section{실험원료}

실험에 사용된 대상 시료는 경상북도 울진에 위치한 보암광산으로부터 채취 하였으며, 채취시료의 광물조성 을 확인하기 위해 고분해능 X-선 회절기(HRXRD, Highresolution X-ray diffraction, X'pert-pro MPD, PANalytical, Netherlands)를 이용해 분석하였다. 전반적인 성분 및 함량
분석은 $\mathrm{X}$-선 형광 분석기(XRF, X-ray fluorescence spectrometry, S2 RANGER, Bruker, Germany)를 이용해 조사하였다. 리튬성분에 대한 정량분석은 유도결합플라즈 마 분광기(ICP, Inductively Coupled Plasma Spectrometer, OPTIMA 7300DV)를 이용해 확인하였다. Fig. 1은 대상 시료에 대한 XRD 분석결과를 나타낸 것으로 주요 구성 광물로는 방해석(calcite, $\mathrm{CaCO}_{3}$ ), 석영(quartz, $\left.\mathrm{SiO}_{2}\right)$, 백 운모(muscovite, $\left(\mathrm{K}\left(\mathrm{OH}, \mathrm{F}_{2}\right)_{2} \mathrm{Al}_{3} \mathrm{Si}_{2} \mathrm{O}_{10}\right)$ ), 인운모(lepidolite, $\left.\left(\mathrm{KLiAl}(\mathrm{OH}, \mathrm{F})_{2} \mathrm{Al}\left(\mathrm{SiO}_{4}\right)_{3}\right)\right)$ 로 조사되었고, 인운모에 리튬 이 집중적으로 분포함을 확인하였다. XRF 분석결과 $\mathrm{Ca}-\mathrm{Si}-$ 계 화합물이 전체의 약 $74 \%$ 이상을 차지함을 확인하였으나 본 연구의 목적 물질인 리튬성분은 XRF 분석으로부터 불검출 되었다. 이는 분석에 사용된 XRF의

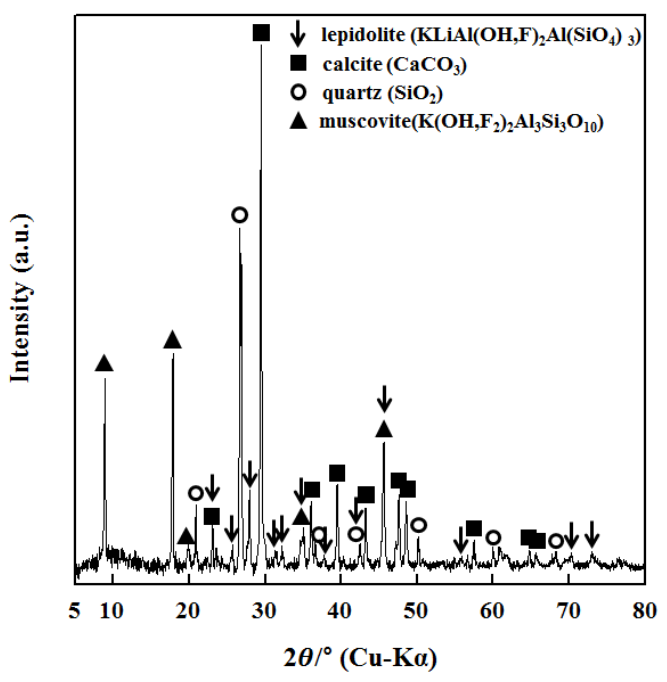

Fig. 1. XRD Patterns of the starting mineral from Boam mine.

Table 1. The results of the ICP and XRF analysis for the starting mineral from Boam mine

\begin{tabular}{ccccccccccccc}
\hline \hline \multicolumn{10}{c}{ Chemical composition } \\
\hline analysis & $\mathrm{ICP}$ & \multicolumn{10}{c}{ XRF } \\
\hline elements & $\mathrm{Li}$ & $\mathrm{Al}_{2} \mathrm{O}_{3}$ & $\mathrm{SiO}_{2}$ & $\mathrm{P}_{2} \mathrm{O}_{5}$ & $\mathrm{~K}_{2} \mathrm{O}$ & $\mathrm{CaO}$ & $\mathrm{MnO}$ & $\mathrm{Fe}_{2} \mathrm{O}_{3}$ & $\mathrm{Rb}_{2} \mathrm{O}$ & $\mathrm{Cs}_{2} \mathrm{O}$ & $\mathrm{MgO}$ \\
\hline contents$(\%)$ & 0.622 & 16.95 & 44.3 & 0.27 & 5.87 & 30.1 & 0.17 & 0.51 & 0.55 & 0.12 & 1.16 \\
\hline
\end{tabular}

Table 2. Physical properties of each minerals in starting mineral

\begin{tabular}{ccccc}
\hline \hline & lepidolite & muscovite & calcite & quartz \\
\hline tenacity & elastic & elastic & brittle & brittle \\
\hline density & $2.8 \sim 2.9$ & $2.77 \sim 2.88$ & 2.71 & 2.65 \\
\hline
\end{tabular}


특성상 원자번호 11 번인 $\mathrm{Na}$ 부터 측정 가능한 $\mathrm{EDXRF}$ (에너지 분산형 x-ray 형광분석기, energy dispersive X-ray fluorescence spectrometry)장비로 XRF기기의 측정 가 능한 원소 분석범위에 리튬이 포함되지 않아 나타난 결 과이다. 따라서 리튬의 함량은 $\mathrm{ICP}$ 를 이용해 평가하였으 며, ICP 분석결과 리튬은 $0.622 \%$ 로 확인되었다(Table 1). $\mathrm{ICP}$ 로부터 확인된 $\mathrm{Li}$ 의 농도는 $\mathrm{Li}_{2} \mathrm{O}$ 로 환산 하였으 며 $1.33 \%$ 로 계산되었다.

Table 2 는 대상 시료에 포함된 4종류 광물의 물리적 특성 중 강도(tenacity)와 밀도(density)를 나타낸 것으로 회수 목적광물인 인운모의 강도특성은 방해석, 석영에 비해 쉽게 부서지지 않는 특성을 가지고 있을 뿐만 아니 라 4종류 광물 중 가장 높은 비중 특성을 확인 하였다. 이에 선택적 분쇄 및 중액선별에 의한 인운모의 선별실 험을 진행하였다(RRUFF, 2013).

\section{실험방법}

대상 시료를 jaw crusher(급광구: $100 \mathrm{~mm}$ (가로) $\times 80$ $\mathrm{mm}$ (세로), 배출구: $100 \mathrm{~mm}$ (가로 $) \times 10 \mathrm{~mm}$ (세로) 를 이 용해 파쇄 하였으며, 파쇄된 산물을 체를 사용하여 +4

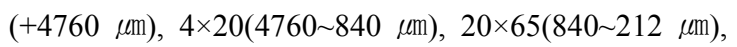
$-65 \operatorname{mesh}(-212 \mu \mathrm{m})$ 의 4 개 구간으로 입도 조정하였 다. 입도 조정된 시료는 각 구간별 무게비율 $(\mathrm{wt} \%), \mathrm{Li}_{2} \mathrm{O}$ 의 품위 및 분포 확인 후, $+4,4 \times 20,20 \times 65 \mathrm{mesh}$ 구간의 산물을 각각 중액선별 실험에 투입하였다(Fig. 2). -65 mesh구간은 입자의 크기가 너무 작기 때문에 중액선별 로는 분리가 어려울 것으로 판단되어 본 연구의 중액선 별 실험대상에서 제외하였다.

중액선별에 사용된 매질(medium)은 비중이 2.967인 1,1,2,2-tetrabromoethane( $98.0 \%$, Junsei)을 희석해 매질의

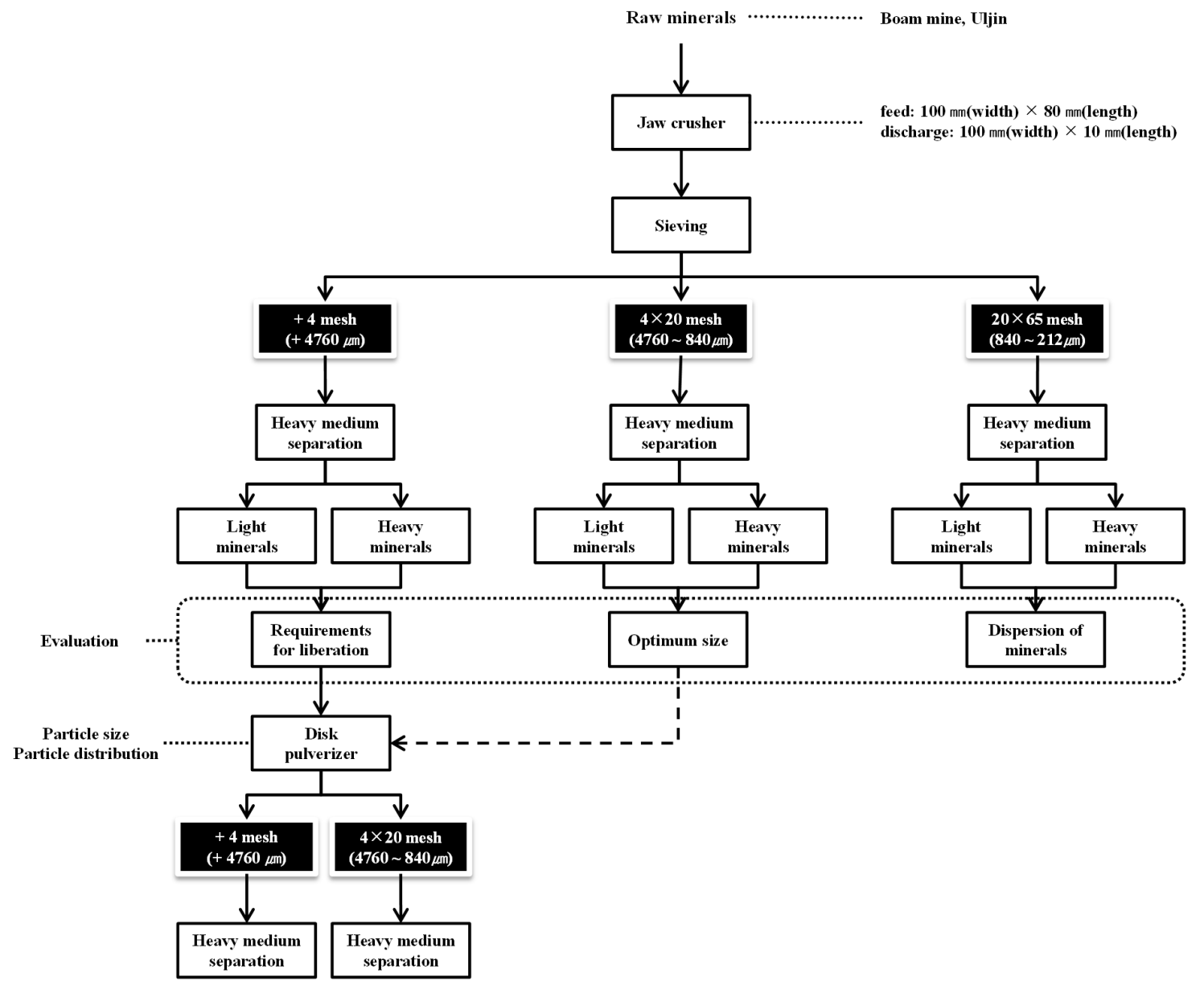

Fig. 2. The flowchart of this research. 
비중을 $2.65,2.70,2.75$ 으로 변화시켜 실험하였으며 침 강시간 $(10 \mathrm{~min}$.$) , 시료의 투입량 (50 \mathrm{~g})$ 및 매질의 량(300 $\mathrm{ml}$ )을 고정하여 $500 \mathrm{ml}$ 용량의 비이커에 투입하였다. 희 석용액으로는 등유(kerosine, density: $0.8 \mathrm{~g} / \mathrm{cm}^{3}$, Junsei) 를 이용하였다.

Jaw crusher 파쇄 후, 중액선별실험에서 리튬의 선별 효율(separation efficiency)이 낮은 +4 mesh 구간의 산 물은 리튬을 포함하는 인운모와 맥석광물의 단체분리를 목적으로 disk pulverizer(UD pulverizer, BICO INC. USA)를 이용해 분쇄하였고, 선별효율은 Schulz가 제안 한 식을 이용해 계산하였다(Wills and Napier-Munn, 2006). disk pulverizer는 disk 간격을 $2.0,2.5,3.0,3.5$ $\mathrm{mm}$ 로 조절하였으며, disk의 회전속도(900 rpm)를 고정 하여 실험하였다. disk pulverizer에 의해 분쇄된 산물은 입도구간별 $(+4,4 \times 20,20 \times 65,-65 \mathrm{mesh})$ 무게비율을 조사하였으며, $+4,4 \times 20$ mesh산물을 각각 중액선별에 투입하였다. 중액선별은 앞서 언급한 선별실험과 동일한 조건으로 침강시간 $(10 \mathrm{~min}$.$) , 시료 투입량 (50 \mathrm{~g})$ 및 매질 $(300 \mathrm{ml})$ 을 고정하고 매질의 비중 $(2.65,2.70,2.75)$ 을 비 교조건으로 실시하였다. 실험을 통해 회수된 부유물과 침강물은 각각 회수하여 에탄올로 세척 후, $105^{\circ} \mathrm{C}$ 에서 $2 \mathrm{hr}$ 건조 후 중량을 측정하였으며, 각 산물별 전 원소분 석을 통해 ICP 분석을 실시하였다.

\section{결과 및 고찰}

Table 3은 jaw crusher를 이용해 대상 시료 $5 \mathrm{~kg}$ 을 파 쇄 후 건식 입도분리 한 결과로서 입도구간별 무게분포 $(\mathrm{wt} \%), \mathrm{Li}_{2} \mathrm{O}$ 의 품위 $(\%)$ 를 나타내었다. 전체 무게 중 $75.1 \%$ 가 +20 mesh 구간에 분포하고, 입자의 크기가 커 질수록 $\mathrm{Li}_{2} \mathrm{O}$ 의 품위가 높은 경향을 나타내었다. 이는 대 상 시료에 포함된 $\mathrm{Li}_{2} \mathrm{O}$ 성분이 인운모에만 집중된 상태 로 존재하고 있으며(Fig. 1), 인운모의 강도(tenacity)특 성이 맥석광물인 방해석, 석영에 비해 쉽게 부서지지 않 는 특성을 가지고 있어 나타난 결과로 판단된다(Table 2). jaw crusher 파쇄 후, 입도별로 분리된 산물 $(+4,4 \times 20$, $20 \times 65 \mathrm{mesh}$ )은 중액에 투입, 침강시간은 $10 \mathrm{~min}$.으로 고정하였으며, 침강물질의 $\mathrm{Li}_{2} \mathrm{O}$ 품위 및 회수율을 확인 하였다. 선별에 사용된 매질의 비중은 Table 2 에 제시된 4 종류 광물의 비중을 고려해 $2.65,2.70,2.75$ 로 조절하 여 실험하였다(Fig. 3).

입도구간에 관계없이 매질의 비중이 높아질수록 $\mathrm{Li}_{2} \mathrm{O}$ 의 품위는 증가, 회수율은 감소되는 경향을 나타내었으 며, $4 \times 20 \mathrm{mesh}$ 구간 산물은 매질 비중 2.70 조건에서 품 위 $4.32 \%$, 회수율 $72.39 \%$ 로 가장 높은 리튬 선별효율 (66.8\%)을 나타내었다(Fig. 3, Fig. 4). 하지만 $+4,20 \times 65$ mesh의 경우, 매질 비중 2.70에서 2.75로 증가함에 따라 $\mathrm{Li}_{2} \mathrm{O}$ 의 회수율이 급격히 감소하는 것으로 확인되었다
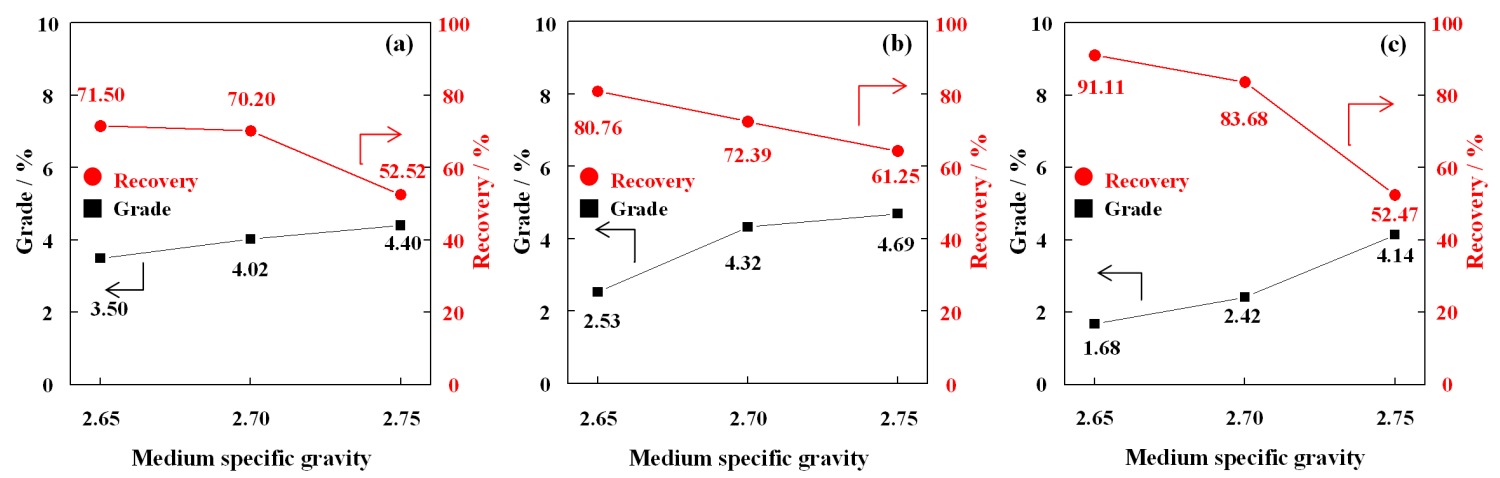

Fig. 3. Grade and recovery for $\mathrm{Li}_{2} \mathrm{O}$ with change of the medium specific gravity ((a) +4 mesh, (b) $4 \times 20$ mesh, (c) $20 \times 65$ mesh).

Table 3. The weight ratio and grade of $\mathrm{Li}_{2} \mathrm{O}$ with change of the size ranges for the starting mineral

\begin{tabular}{ccccc}
\hline \hline Particle size & $\begin{array}{c}+4 \text { mesh } \\
(+4760 \mu \mathrm{m})\end{array}$ & $\begin{array}{c}4 \times 20 \text { mesh } \\
(4760 \sim 840 \mu \mathrm{m})\end{array}$ & $\begin{array}{c}20 \times 65 \text { mesh } \\
(840 \sim 212 \mu \mathrm{m})\end{array}$ & $\begin{array}{c}-65 \text { mesh } \\
(-212 \mu \mathrm{m})\end{array}$ \\
\hline weight ratio $(\mathrm{wt} \%)$ & 48.60 & 26.50 & 11.00 & 13.90 \\
\hline grade $\left(\mathrm{Li}_{2} \mathrm{O}, \%\right)$ & 1.46 & 1.32 & 1.05 & 1.11 \\
\hline
\end{tabular}


(+4 mesh: $70.20 \rightarrow 52.52 \%, 20 \times 65$ mesh: $83.68 \rightarrow$ $52.47 \%)$. 이 중 +4 mesh는 매질비중에 관계없이 리튬의 선별효율이 $45 \%$ 이하로 $4 \times 20,20 \times 65$ mesh구간에 비해 전체적으로 낮게 확인되었다(Fig. 4). 이러한 결과는 jaw crusher를 통해 파쇄된 +4 mesh 구간의 인운모가 방해석,

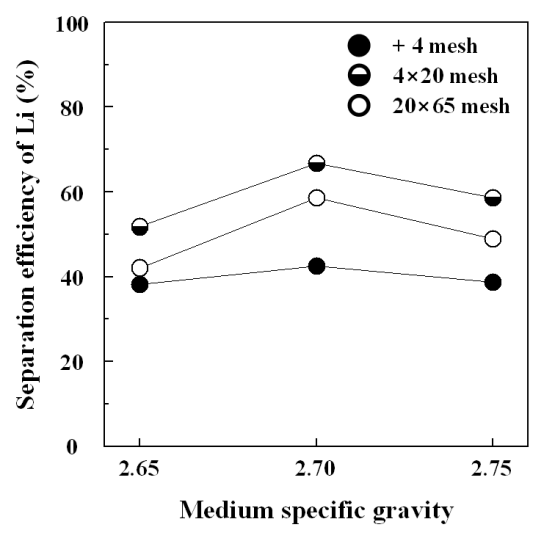

Fig. 4. Separation efficiency for Li with change of the medium specific gravity and particle size.

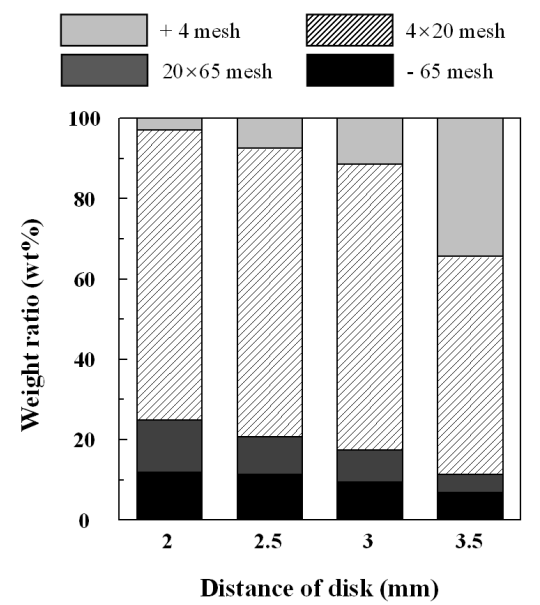

Fig. 5. Weight ratio of $\mathrm{Li}_{2} \mathrm{O}$ with change of the distance of disk.
석영, 백운모와의 단체분리가 부족해 발생된 결과로 판 단된다(Amarante et al., 1999). 20×65 mesh구간은 +4 mesh에 비해 대체적으로 리튬의 선별효율이 높게 나타 났으나, 선별효율이 가장 높은 구간(비중: 2.70 , 선별효율: $58.7 \%$ )에서의 $\mathrm{Li}_{2} \mathrm{O}$ 의 품위가 $2.42 \%$ (회수율: $83.68 \%$ )로 경제적 활용가치가 있는 $4 \% \mathrm{Li}_{2} \mathrm{O}$ 에 비해 낮게 확인되었 다. 이는 입경이 작아짐에 따라 중액과 입자간의 표면마 찰(surface friction)의 영향력이 증가되고 입자의 침강속 도가 감소함에 따라 발생된 결과로 판단되며(Wills and Napier-Munn, 2006), 단순히 중액만을 이용한 선별실험 으로는 $\mathrm{Li}_{2} \mathrm{O}$ 의 품위 및 회수율 향상은 어렵다고 판단된 다. 따라서 중액선별에 의한 리튬의 선별효율이 가장 높 은 $4 \times 20 \mathrm{mesh}$ 구간과 $\mathrm{Li}_{2} \mathrm{O}$ 의 품위 및 회수율 향상이 어 려운 $20 \times 65 \mathrm{mesh}$ 구간은 이후 실험에서 제외하였으며, +4 mesh 산물에 대해서만 $\mathrm{Li}_{2} \mathrm{O}$ 의 품위 및 회수율을 향 상시키기 위한 분쇄실험을 진행하였다.

+4 mesh구간 산물에 대한 분쇄실험은 중액선별시 리 튬의 선별효율이 높은 $4 \times 20 \mathrm{mesh}$ 구간의 무게비율이 많 고, 중액선별이 어려운 $-20 \mathrm{mesh}$ 구간의 발생이 적은 분쇄조건을 확인하기 위한 목적으로 disk pulverizer을 이용해 실험하였다. Fig. 5는 jaw crusher로 분쇄된 산물 중 +4 mesh구간의 산물을 disk pulverizer에 투입하고, disk 간격을 $2.0,2.5,3.0,3.5 \mathrm{~mm}$ 로 변화시켜 분쇄하여 $+4,4 \times 20,20 \times 65,-65$ mesh구간으로 건식 입도분리 한 결과이다. 모든 분쇄조건에서 disk 간격보다 더 큰 입자 크기를 갖는 +4 mesh(aperture size: $4760 \mu \mathrm{m}$ ) 입도구간 에서도 분쇄산물이 존재함을 알 수 있었으며, 이는 disk pulverizer 기기의 분쇄 특성에 의해 발생된 것으로 판단 된다.

$4 \times 20$ mesh 구간 산물의 무게비율은 $3.0 \mathrm{~mm}$ 이하의 간격에서 disk 간격변화에 관계없이 약 $70 \mathrm{wt} \%$ 정도를 나타내었으나 $3.5 \mathrm{~mm}$ 구간에서 급격히 감소하였다(3.0 $\mathrm{mm}: 71.0 \mathrm{wt} \%, 3.5 \mathrm{~mm}: 54.1 \mathrm{wt} \%)$. 이러한 결과는 disk 간격이 넓어질수록 분쇄대상에 전달되는 충격 및 전단력 이 감소되어 나타난 것으로 판단된다. 따라서 $4 \times 20$ mesh 구간 산물이 $70 \mathrm{wt} \%$ 이상 회수되는 $3.0 \mathrm{~mm}$ 이하의 간격조건 중 $20 \mathrm{mesh}$ 를 통과되는 무게비율이 가장 적은

Table 4. The weight ratio and grade of $\mathrm{Li}_{2} \mathrm{O}$ with change of the size ranges for the passing +4 mesh mineral after grinding by disk pulverizer

\begin{tabular}{ccccc}
\hline \hline Particle size & $\begin{array}{c}+4 \text { mesh } \\
(+4760 \mu \mathrm{m})\end{array}$ & $\begin{array}{c}4 \times 20 \text { mesh } \\
(4760 \sim 840 \mu \mathrm{m})\end{array}$ & $\begin{array}{c}20 \times 65 \text { mesh } \\
(840 \sim 212 \mu \mathrm{m})\end{array}$ & $\begin{array}{c}-65 \text { mesh } \\
(-212 \mu \mathrm{m})\end{array}$ \\
\hline weight ratio $(\mathrm{wt} \%)$ & 11.48 & 71.00 & 8.04 & 9.48 \\
\hline grade $\left(\mathrm{Li}_{2} \mathrm{O}, \%\right)$ & 1.95 & 1.50 & 1.03 & 0.89 \\
\hline
\end{tabular}


$3.0 \mathrm{~mm}$ 조건(+4 mesh: $11.48 \mathrm{wt} \%, 4 \times 20$ mesh: 71.00 wt $\%, 20 \times 65$ mesh: $8.04 \mathrm{wt} \%,-65$ mesh: $9.48 \mathrm{wt} \%)$ 을 disk pulverizer의 분쇄조건으로 설정하였다. Table 4는 disk 간격 $3 \mathrm{~mm}$ 조건에서 분쇄한 +4 mesh 산물을 입도 구간별 무게분포 및 $\mathrm{Li}_{2} \mathrm{O}$ 의 품위를 나타낸 결과이다. +4 mesh 산물의 전체 무게 중 $82 \mathrm{wt} \%$ 이상이 $+20 \mathrm{mesh}$ 에 분포하였고, 입도가 커질수록 $\mathrm{Li}_{2} \mathrm{O}$ 의 품위가 증가하였 다. 이는 앞서 언급하였듯이 인운모와 맥석광물의 강도 특성 차이에 의해 발생된 결과로 판단된다(Table 2).

Fig. 6은 disk pulverizer의 disk의 간격이 $3.0 \mathrm{~mm}$ 인 조건에서 회수된 분쇄산물 중 $+4,4 \times 20$ mesh 구간산물 을 대상으로 매질비중 변화 $(2.65,2.70,2.75)$ 에 따른 실 험결과이다. Fig. 3(a, b)와 마찬가지로 입도에 관계없이 매질비중이 높아질수록 $\mathrm{Li}_{2} \mathrm{O}$ 의 품위는 증가, 회수율은 점차 감소되는 경향을 나타냈으며 동일한 매질의 비중조 건에서 입도가 커질수록 $\mathrm{Li}_{2} \mathrm{O}$ 의 품위, 회수율이 증가되 었다. 이는 disk pulverizer에 의한 분쇄 후에도 맥석과 단체분리가 부족한 인운모는 매질의 비중이 커질수록 부 유되며, 비중선별의 선별효율은 시료의 입자크기가 커질 수록 증가되기 때문에 나타난 결과로 판단된다(Wills and Napier-Munn, 2006).

$4 \times 20 \mathrm{mesh}$ 구간의 경우, 비중 2.70 조건에서 리튬의 선 별효율 $67.9 \%, \mathrm{Li}_{2} \mathrm{O}$ 품위 $4.61 \%$, 회수율 $71.37 \%$ 로 나 타났으며, 이러한 결과는 jaw crusher를 통해 회수된 4× 20 mesh 산물의 중액선별 결과와 큰 차이가 없었다. 하 지만 +4 mesh구간 산물의 경우, 매질비중 2.70 이상의 조건에서 jaw crusher 파쇄 후 바로 투입된 중액선별에 비해 $\mathrm{Li}_{2} \mathrm{O}$ 의 품위, 회수율 및 리튬의 선별효율이 각각 $0.8 \%, 10 \%, 33 \%$ 정도 향상됨을 확인하였다(Fig. $3(\mathrm{a})$, Fig. 4, Fig. 6(a), Fig. 7). 이는 이 입도범위에서 인운모
표면에 부착된 맥석광물이 disk pulverizer에 의한 분쇄 를 통해 단체분리가 잘 이루어져 나타난 결과로 판단된 다. 따라서 중액선별을 이용한 보암광산 리튬광물의 품 위 향상을 위해서는 파/분쇄조건으로, jaw crusher를 이 용한 광물 파쇄 후 인운모의 입자크기가 +4 mesh로 존 재 가능한 상태에서 맥석과의 단체분리가 용이한 분쇄조 건의 적용이 적합하다고 판단된다. 본 연구를 통해 얻어진 $+4,4 \times 20 \mathrm{mesh}$ 구간에 대한 최적 중액선별결과(recovery, grade)를 이용한 회수율(yield)은 약 $48.33 \%, \mathrm{Li}_{2} \mathrm{O}$ 의 품 위는 $4.51 \%$ 로 확인되었다. 이에 경제적 가치가 있는 품 위 $4 \%$ 이상의 $\mathrm{Li}_{2} \mathrm{O}$ 의 분리가 파/분쇄 후 중액선별만으로 도 가능함을 확인하였다.

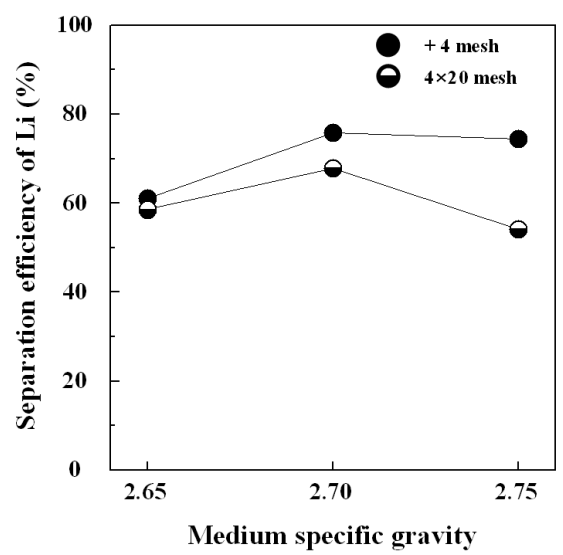

Fig. 7. Separation efficiency for Li with change of the medium specific gravity and particle size.

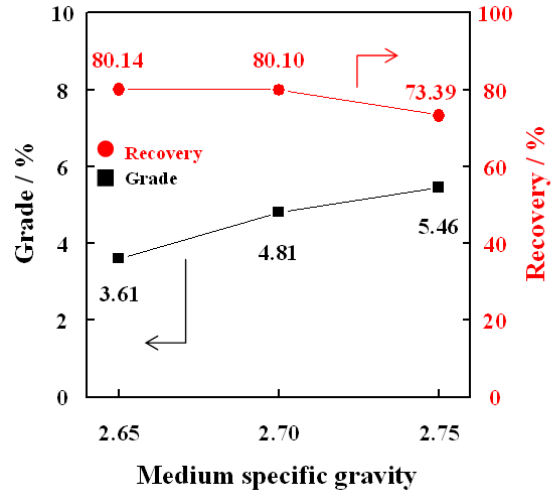

(a)

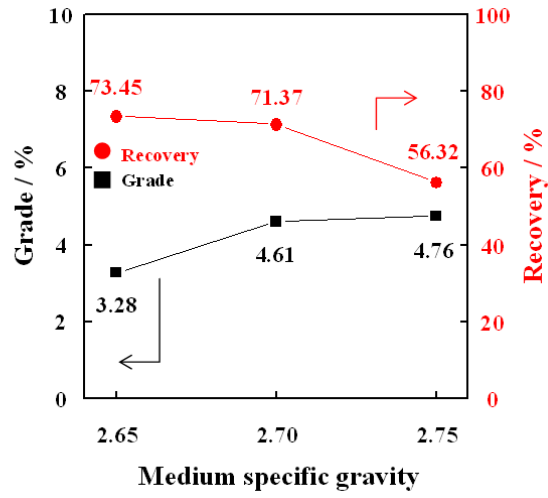

(b)

Fig. 6. Grade and recovery for $\mathrm{Li}_{2} \mathrm{O}$ with change of the medium specific gravity ((a) +4 mesh, (b) $4 \times 20$ mesh). 


\section{결 론}

리튬의 품위가 $0.622 \%\left(\mathrm{Li}_{2} \mathrm{O}\right.$ 로 환산 시 $\left.1.33 \%\right)$ 인 국내 저품위 리튬함유광물로부터 경제적으로 활용 가능한 $\mathrm{Li}_{2} \mathrm{O}$ (품위: $4 \%$ 이상)를 회수하기 위해 대상광석을 jaw crusher를 이용해 파쇄 후 입도구간 $(+4,4 \times 20,20 \times 65)$ 별 중액선별을 실시하였다. 중액선별 후 $\mathrm{Li}_{2} \mathrm{O}$ 의 품위, 회수 율 및 리튬의 선별효율이 높은 입도구간을 조사, 중액선 별에 의해 선별이 어려운 입도구간을 확인한 후 추가 분 쇄공정을 통해 중액선별을 실시하여 다음과 같은 결론을 얻었다.

1. 저품위 리튬함유광물에 포함된 광물의 종류로는 방해석 (calcite, $\mathrm{CaCO}_{3}$ ), 석영(quartz, $\mathrm{SiO}_{2}$ ), 백운모(muscovite, $\left.\left(\mathrm{K}\left(\mathrm{OH}, \mathrm{F}_{2}\right)_{2} \mathrm{Al}_{3} \mathrm{Si}_{2} \mathrm{O}_{10}\right)\right)$, 인운모(lepidolite, $\left(\mathrm{KLiAl}(\mathrm{OH}, \mathrm{F})_{2}\right.$ $\left.\left.\mathrm{Al}\left(\mathrm{SiO}_{4}\right)_{3}\right)\right)$ 로 확인되었으며, 리튬의 성분은 인운모에 만 분포하였다.

2. jaw crusher 파쇄된 산물의 입도구간별 중액선별을 실시한 결과, $4 \times 20 \mathrm{mesh}$ 구간 산물이 매질 비중 2.70 조건에서 $\mathrm{Li}_{2} \mathrm{O}$ 품위 $4.32 \%$, 회수율 $72.39 \%$ 로 가장 높은 리튬 선별효율 $(66.8 \%)$ 을 나타냈다. $+4 \mathrm{mesh}$ 의 경우, 중액 비중이 증가함에 따라 $\mathrm{Li}_{2} \mathrm{O}$ 의 회수율이 급 격히 감소되어(비중 2.70: $70.20 \rightarrow$ 비중 $2.75:$ $52.52 \%$ ), 인운모와 맥석과의 단체분리를 위한 분쇄실 험이 필요함을 확인, 단체분리를 위해 disk pulverizer 를 이용한 분쇄를 실시하였다.

3. disk pulverizer에 의한 분쇄는 $4 \times 20 \mathrm{mesh}$ 구간 산물 이 $70 \%$ 이상 회수되는 $3.0 \mathrm{~mm}$ 이하의 disk 간격조건 중 $20 \mathrm{mesh}$ 를 통과되는 무게비율이 가장 적은 $3.0 \mathrm{~mm}$ 조건을 분쇄조건으로 설정하였으며, $+4 \mathrm{mesh}$ 산물의 전체 무게 중 $82 \mathrm{wt} \%$ 이상이 $+20 \mathrm{mesh}$ 에 분포하였다.

4. disk pulverizer에 의해 분쇄 후 회수된 분쇄산물 $(+4$, $4 \times 20 \mathrm{mesh}$ )의 중액실험에서 $+4 \mathrm{mesh}$ 구간 산물은 매 질비중 2.70조건에서 jaw crusher 파쇄 후 바로 투입 된 중액선별에 비해 $\mathrm{Li}_{2} \mathrm{O}$ 의 품위, 회수율 및 리튬의 선별효율이 각각 $0.8 \%, 10 \%, 33 \%$ 정도 향상됨을 확 인되었다 $\left(\mathrm{Li}_{2} \mathrm{O}\right.$ 품위: $4.8 \%$, 회수율: $\left.80 \%\right)$. 이는 +4 mesh 범위에서 대상 시료에 포함된 인운모와 맥석 간 단체분리가 disk pulverizer에 의해 이루어져 나타 난 것으로 판단된다.

5. 본 실험을 통해 얻어진 $+4,4 \times 20 \mathrm{mesh}$ 구간에 대한 최적 중액선별결과(recovery, grade)로부터 계산된 회 수율(yield)은 약 $48.33 \%, \mathrm{Li}_{2} \mathrm{O}$ 의 품위는 $4.51 \%$ 로, 경제적 가치가 있는 품위 $4 \%$ 이상의 $\mathrm{Li}_{2} \mathrm{O}$ 의 분리가 파/분쇄 후 중액선별만으로도 가능함을 확인하였다.

\section{사 사}

이 연구는 한국지질자원연구원에서 수행중인 "국내 희유금속자원 탐사 및 활용기술개발”과제의 지원으로 수행되었으며 이에 감사드립니다.

\section{References}

Amarante, M.M., Sousa, A.B. and Leite, M.M., 1999, "Processing a Spodumene ore to obtain lithium concentrates for addition to glass and ceramic bodies," Minerals Engineering, Vol. 12, No. 4, pp. 433-436.

Bale, M.D. and May, A.V., 1989, "Processing of ores to produce tantalum and lithium," Minerals Engineering, Vol. 2, No. 3, pp. 299-320.

Brandt, F. and Haus, R., 2010, "New concepts for lithium minerals processing," Minerals Engineering, Vol. 23, pp. 659-661.

Choi, J.H., Kim, W.T., Chae, W.R., Kim, S.B. and Kim, H.J., 2012, "Electrostatically Controlled Enrichment of Lepidolite via Flotation," Materials Transaction, Vol. 53, No. 12, pp. 2191-2194.

Chon, U., Han, G.C., Kim, K.Y. and Kim, K.H., 2010, "Current Status of Lithium Resources," J. of Korean Inst. of Resources Recycling, Vol. 19, No. 3, pp. 3-8.

Ebensperger, A., Maxwell, P. and Moscoso, C., 2005, "The lithium industry: Its recent evolution and future prospects," Resources Policy, Vol. 30, pp. 218-231.

Jeon, H.S., Park, C.H., Han, O.H., Kim, B.G. and Kim, J.H., 2011, "Froth Flotation of Molybdenum Ore by Multistage Grinding Process," J. of The Korean Society of Mineral and Energy Resources Engineering, Vol. 48, No. 1, pp. 25-33.

Kesler, S.E., Gruber, P.W., Medina, P.A., Keoleian, G.A., Everson, M.P. and Wallington, T.J., 2012, "Global lithium resources: Relative importance of pegmatite, brine and other deposits," Ore Geology Reviews, Vol. 48, pp. 55-69.

Lee, K.H., Jeon, H.S., Baek, S.H. and Kim, S.G., 2012, "Development of Flotation System for Utilization of Low Grade Lithium Ore," J. of the Mineralogical Society of Korea, Vol. 25, No. 0, pp. 1-10.

RRUFF, 2013.12.09, http://rruff.info.

Wang, Y.H. and Yu, F.S., 2007, "Effects of Metallic Ions on the Flotation of Spodumene and Beryl," J. of China University of Mining \& Technology, Vol. 17, No. 1, pp. 35-39.

Wills, B.A. and Napier-Munn, T.J., 2006, WILLS Mineral Processing Technology, $7^{\text {th }}$ Ed., Oxford: ButterworthHeinemann, p. 18, 226. 


\section{이 정 훈}

현재 강원대학교 에너지 - 자원공학과 석사과정 (本 學會誌 第50券 第6号 參照)

\section{임 진 호}

현재 강원대학교 에너지 - 자원공학과 석사과정 (本 學會誌 第50券 第6号 參照)

\section{이 재 령}

현재 강원대학교 에너지·자원공학과 부교수 (本 學會誌 第50券 第6号 參照)

\section{김 영 진}

현재 강원대학교 에너지 - 자원공학과 박사과정 (本 學會誌 第50券 第6号 參照)

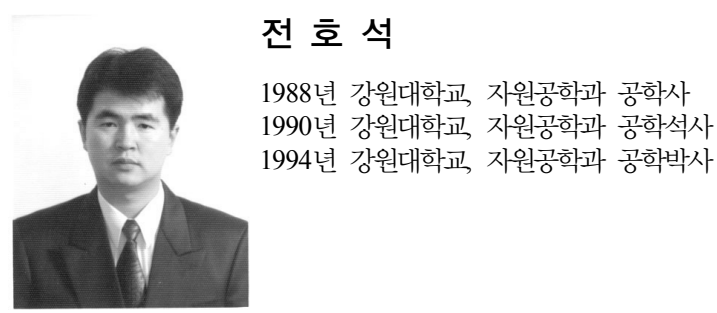

현재 한국지질자원연구원 광물자원연구본부 책임연구원 과학기술연합대학교 자원순환공학과 교수

(E-mail; hsjeon@kigam.re.kr) 